\title{
High-strength Reinforced Concrete Matrices, Hardening Under Pressure
}

\author{
Gennadiy Murashkin ${ }^{1}$, Antonina Snegireva ${ }^{2}$, and Dmitriy Kretov ${ }^{3, *}$ \\ ${ }^{1}$ Samara State Technical University, Academy of Architecture and Civil Engineering, 194 \\ Molodogvardeyskaya Str., Samara, Russian Federation, 443001 \\ ${ }^{2}$ Belebey branch of Samara State Technical University (Republic of Bashkortostan), 11 Sovetskaya \\ Str., Belebey, Russian Federation, 452000 \\ ${ }^{3}$ Joint Stock Company Space Rocket Centre Progress, 18 Zemetsa Str., Samara, Russia, 443009
}

\begin{abstract}
The paper analyses ways of increasing strength and durability of reinforced concrete matrices for explosive stamping. One of the means to increase the strength of the structure is a technological method of hardening concrete mixture processing. This technique is known as concrete hardening under pressure. The research reveals advantages and disadvantages of this method. It shows that the improvement of matrix characteristics is achieved through engineering changes. The authors describe their design of the matrix, to which they additionally install a compensation layer and a hydraulic chamber. The chamber allows creating pressure inside the structure not only at the moment of its manufacture, but also at any moment of its operation. The paper further describes the developed method of calculating ring-shaped reinforced concrete matrices with a compensation layer. It proposes equations of a matrix and its separate elements motion, necessary for other calculations. The results of calculation of the matrix and its developed structure are described. Graphs of matrix motion and graphs of relative deformations in time done in MathCAD complex are given.
\end{abstract}

\section{Introduction}

Currently usage of high-strength concrete class B60 and higher is gaining its popularity on the territory of the Russian Federation. For Russia, regulatory documentation for quality control of high-strength concrete began to operate from 2014 (GOST 31914-2012). Considering the normative documentation of the European Union (EN 206-1), which is in force since 2000, it is possible to find classes of concrete $\mathrm{C} 100 / 115$, which corresponds to the national class B100. Constructions from such concrete are made by using highly active binders such as alkaline cement, Portland cement, cementious substances with low water absorption and polymeric binders. In the world practice, such concretes are called High Performance Concrete (HPC) [1].

However, it is possible to produce high-strength concrete due to the use of technological methods for processing the concrete mix. Nowadays, the most effective method has been

\footnotetext{
${ }^{*}$ Corresponding author: kretdima@rambler.ru
} 
identified, such as the use of pressure on the mixture, to obtain the required strength [2]. This is achieved by reducing the water-cement ratio - the pressure removes excess moisture from the mixture. Also, the porosity of concrete decreases by several times, the number of defects in the structure decreases, thus the mixture becomes denser and additional chemical reactions develop. As a result with the use of ordinary aggregates (as for concrete class B30), we obtain increased strength, reliable adhesion of concrete to the reinforcement and increased frost resistance. Thus, it allows solving the problem of lack of the necessary raw materials base of high-quality components.

At present, there is a problem of the lack of molds for the manufacture of concrete, hardened under pressure. There are only devices for obtaining small-sized products (curbs, paving slabs, micro piles, columns without consoles).

The use of concrete, hardened under pressure is possible not only in the construction sector. There are examples of the use of concrete, hardened under pressure for the manufacture of reinforced concrete matrices for hydro explosion stamping [3]. Ferroconcrete matrices replace metal analogues, due to which the metal consumption and weight of the structure decrease and it becomes possible to manufacture large-size matrices near the stamping site [4].

It is also worth noting the economic benefits of using advanced reinforced concrete matrices made of concrete, hardened under pressure. It is possible to achieve this benefit at experimental small-scale production, in such areas as rocket engineering and aircraft construction [5].

However, there is a problem of multiple use of reinforced concrete matrices. In the process of stamping, concrete undergoes uneven critical loads and breaks down in certain areas, which affects the further quality of the products. Therefore, the search for ways to increase the strength and durability of reinforced concrete matrices is very relevant.

\section{Research Methods}

\subsection{Design Description of the Matrix}

Figure 1 shows circular reinforced concrete matrix, consisting of metal rings and concrete filling between them.

Metal lids bolted together cover the top and bottom of the matrix. The lower cover is welded to the metal rings with intermittent welds. To increase the bearing capacity of the matrix, the concrete sector is additionally reinforced.

A significant difference from analogues is the device in the design of the circular reinforced concrete matrix of the hydraulic tank in order to create pressure on the concrete at the time of hardening. The camera is located from the inside of the outer ring. After the concrete is poured, a hydraulic fluid is supplied to it via pumping equipment through a choke and a non-return valve. The tank, increasing in volume, displaces excess water from concrete through gaps between the bottoms and rings. 


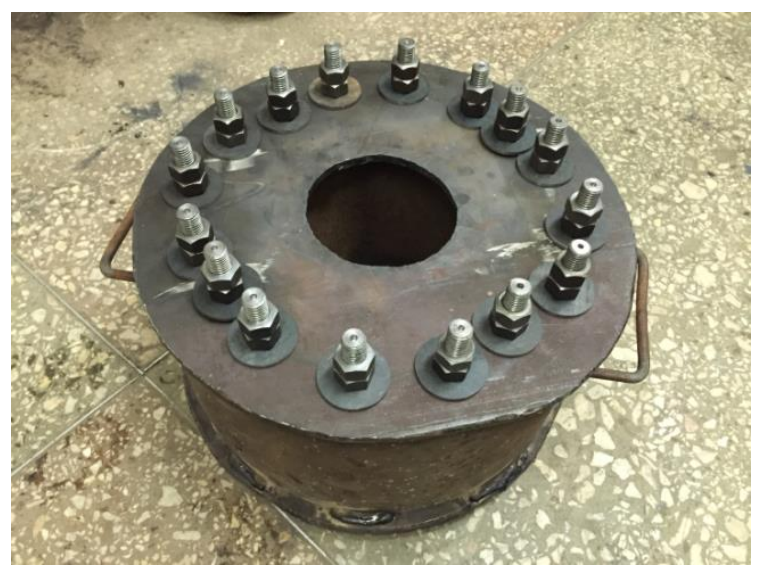

Fig. 1. Reinforced concrete matrix.

This improvement in design contributes to the strength of the concrete sector.

In addition to the above mentioned information, the inner ring on the concrete side is glued with a compensating layer of technical rubber. The task of this layer is a more uniform transfer of the load to the concrete, which prevents local destruction and also contributes to the strength increase.

The matrix described above is an invention $[6,7]$.

\subsection{Mathematical Model}

The mathematical model of reinforced concrete ring matrices is represented as a multilayered construction that perceives impulse (explosive) loads.

For further calculation, the limit state of a particular sector, which is formed as a result of cracks in the concrete, was considered. The design scheme of a four-layer annular reinforced concrete matrix is shown in Figure 2.

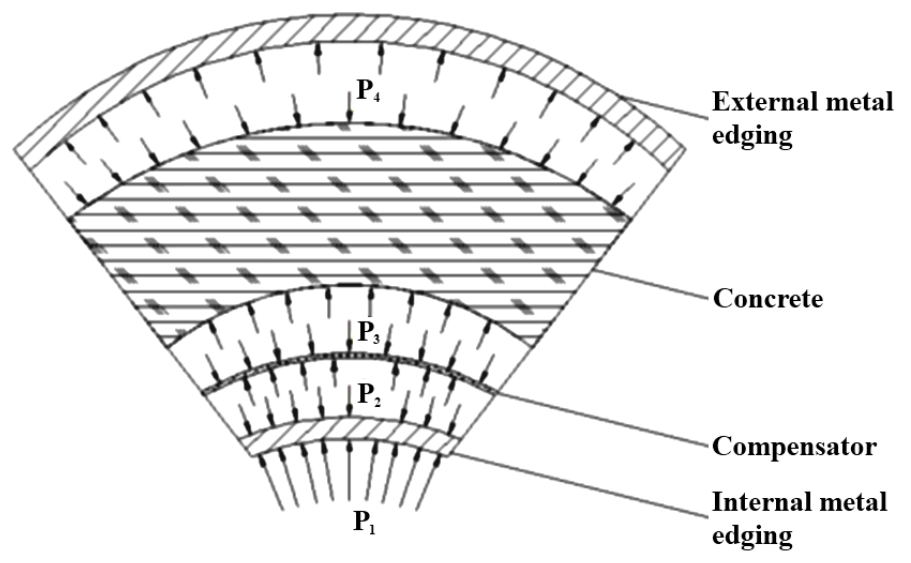

Fig. 2. Mathematical model of reinforced concrete matrix.

The calculation is carried out according to the procedure developed in [8], taking into account the work of the additional compensation layer. These changes are described in detail in [9]. For the calculation we present the equations of motion of the matrix as a whole, the inner ring separately and the outer ring with the concrete sector. Motion 
equations are differential equations, which solutions make it possible to calculate the strain values at any time.

Motion equation of the inner ring:

$$
\ddot{y} \cdot \delta_{1} \cdot \rho_{s}+\dot{y} \cdot \rho_{0} \cdot C_{0}+y \cdot \frac{\delta_{1}}{r^{2}} \cdot E_{s}=2 \cdot P_{m} \cdot e^{-\frac{t}{\theta}}-P_{2},
$$

Motion equation of the outer ring:

$$
\ddot{y} \cdot \delta_{2} \cdot \rho_{s}+y \cdot \frac{\delta_{2}}{R \cdot r} \cdot E_{s}=P_{4},
$$

Motion equation of the compensation layer:

$$
\ddot{y} \cdot \delta_{p} \cdot \rho_{p}+y \cdot \frac{\delta_{p}}{\left(r+\delta_{1}\right)^{2}} \cdot E_{p}=P_{2}-P_{3} \cdot \frac{r+\delta_{1}}{r},
$$

Motion equation of concrete sector:

$$
\ddot{y} \cdot \delta_{b} \cdot \rho_{b}=P_{3} \cdot \frac{r+\delta_{1}}{r}-P \cdot \frac{R}{r},
$$

In order to write the general motion equation of the entire matrix, it is necessary to perform the substitution of equations (1), (2), (3) in equation (4). Then the general motion equation of the matrix will look like this:

$\ddot{y} \cdot\left(\delta_{1} \cdot \rho_{s}+\delta_{p} \cdot \rho_{p}+\delta_{b} \cdot \rho_{b}+\delta_{2} \cdot \rho_{s} \cdot \frac{R}{r}\right)+\dot{y} \cdot \rho_{0} \cdot C_{0}+y \cdot\left(\frac{\delta_{1}}{r^{2}} \cdot E_{s}+\frac{\delta_{p}}{\left[r+\delta_{1}\right]^{2}} \cdot E_{p}+\frac{\delta_{2}}{R \cdot r} \cdot E_{s}\right)=2 \cdot P_{m} \cdot e^{-\frac{t}{\theta}}$

Expression (5) can be written in the form of a second-order nonlinear differential equation:

$$
\ddot{y}+p_{k} \cdot \dot{y}+q_{k} \cdot y=T_{k} \cdot e^{-\frac{t}{\theta}},
$$

in which $p_{k}, q_{k}, T_{k}$ - numerical coefficients.

Solving equation, we get general solution:

$$
y=e^{\alpha \cdot t} \cdot\left(C_{1} \cdot \cos [\beta \cdot t]+C_{2} \cdot \sin [\beta \cdot t]\right)+A \cdot e^{-\frac{t}{\theta}},
$$

in which $\alpha, \beta, A$ - numerical coefficients.

Taking into account the initial conditions and reducing the small quantities, which have lower values, equation (7) takes the form:

$$
y=A \cdot B \cdot e^{\alpha \cdot t} \cdot \sin (\beta \cdot t+\varphi),
$$

in which $B, \varphi$ - numerical coefficients.

\section{Results}

The chosen mathematical model was transferred to the application for mathematical and engineering calculations MathCAD 14. The calculation was made for a matrix with the following dimensions: the internal diameter is $227 \mathrm{~mm}$; the outer diameter is $426 \mathrm{~mm}$. Seamless pipes of $426 * 11$ and $245 * 9$ diameter were used (GOST 8732-78). Concrete was reinforced with rods diameter 16 class A-400 (GOST 5781-82). The diameter of there in for reinforcement ring is $320 \mathrm{~mm}$.

The necessary character is tics of materials and variable values for calculation are presented in the Table 1. 
Table 1. Characteristics of ferroconcrete ring matrice.

\begin{tabular}{|l|c|c|}
\hline \multicolumn{1}{|c|}{ Parameter description } & $\begin{array}{c}\text { Unit of } \\
\text { measurement }\end{array}$ & $\begin{array}{c}\text { Variable } \\
\text { value }\end{array}$ \\
\hline The radius of the outer ring of the matrix $R$ & $\mathrm{~m}$ & 0,202 \\
\hline The radius of the inner ring of the matrix $r$ & $\mathrm{~m}$ & 0,1135 \\
\hline Thickness of outer metal ring $\delta_{2}$ & $\mathrm{~m}$ & 0,011 \\
\hline Thickness of inner metal ring $\delta_{1}$ & $\mathrm{~m}$ & 0,009 \\
\hline Thickness of concrete ring $\delta_{b}$ & $\mathrm{~m}$ & 0,0795 \\
\hline Thickness of rubber layer $\delta_{p}$ & $\mathrm{mg} / \mathrm{m}^{2}$ & 0,002 \\
\hline Elasticity modulus of steel $E_{s}$ & $\mathrm{~kg} / \mathrm{m}^{2}$ & $2 \cdot 10^{10}$ \\
\hline The elastic modulus of rubber $E_{p}$ & $\mathrm{~kg} / \mathrm{m}^{3}$ & 7800 \\
\hline Specific gravity of steel $\gamma_{s}$ & $\mathrm{~kg} / \mathrm{m}^{3}$ & 2400 \\
\hline Specific gravity of concrete $\gamma_{b}$ & $\mathrm{~kg} / \mathrm{m}^{3}$ & 1220 \\
\hline Specific weight of rubber $\gamma_{p}$ & $\mathrm{~kg} / \mathrm{m}^{3}$ & 1000 \\
\hline Specific weight of water $\gamma_{0}$ & & \\
\hline
\end{tabular}

The calculation was made for different values of the charge $q$. The results of the calculation are presented in the Table 2 .

Table 2. The results of calculating the reinforced concrete ring matrix.

\begin{tabular}{|c|c|c|c|c|c|}
\hline \multirow{2}{*}{$\begin{array}{l}\text { Measurement } \\
\text { parameters }\end{array}$} & \multirow{2}{*}{$\begin{array}{c}\text { Unit of } \\
\text { measure } \\
\text { ment }\end{array}$} & \multicolumn{4}{|c|}{ Charge quantity $q, \mathrm{~kg} / \mathrm{m}$} \\
\hline & & 0,01 & 0,02 & 0,03 & 0,04 \\
\hline $\begin{array}{l}\text { Overshoot pressure of } \\
\text { falling impulsive } \\
\text { wave } P_{m}\end{array}$ & $\frac{\mathrm{kg}}{\mathrm{m}^{2}}$ & $7,833 \cdot 10^{6}$ & $10,02 \cdot 10^{6}$ & $11,57 \cdot 10^{6}$ & $12,81 \cdot 10^{6}$ \\
\hline $\begin{array}{l}\text { Dynamic density of } \\
\text { steel } \rho\end{array}$ & \multirow{4}{*}{$\frac{\mathrm{kg} \cdot \mathrm{c}^{2}}{\mathrm{~m}^{4}}$} & \multicolumn{4}{|c|}{795,379} \\
\hline $\begin{array}{l}\text { Dynamic density of } \\
\text { concrete } \rho_{b}\end{array}$ & & \multicolumn{4}{|c|}{244,732} \\
\hline $\begin{array}{l}\text { Dynamicdensity of the } \\
\text { rubber } \rho_{p}\end{array}$ & & \multicolumn{4}{|c|}{124,405} \\
\hline $\begin{array}{l}\text { Dynamic density of } \\
\text { water } \rho_{0}\end{array}$ & & \multicolumn{4}{|c|}{101,972} \\
\hline Coefficient $p_{k}$ & - & \multicolumn{4}{|c|}{$3,436 \cdot 10^{3}$} \\
\hline Coefficient $q_{k}$ & - & \multicolumn{4}{|c|}{$5,554 \cdot 10^{8}$} \\
\hline Coefficient $T_{k}$ & - & $3,692 \cdot 10^{5}$ & $4,722 \cdot 10^{5}$ & $5,453 \cdot 10^{5}$ & $6,039 \cdot 10^{5}$ \\
\hline Coefficient $A$ & - & $5,234 \cdot 10^{-5}$ & $9,654 \cdot 10^{-5}$ & $13,72 \cdot 10^{-5}$ & $17,55 \cdot 10^{-5}$ \\
\hline Coefficient $\alpha$ & - & \multicolumn{4}{|c|}{$-1,718 \cdot 10^{3}$} \\
\hline Coefficient $\beta$ & - & \multicolumn{4}{|c|}{$2,35 \cdot 10^{4}$} \\
\hline Coefficient $B$ & - & 3,573 & 2,975 & 2,682 & 2,496 \\
\hline Coefficient $\varphi$ & - & $-0,284$ & $-0,343$ & $-0,382$ & $-0,412$ \\
\hline
\end{tabular}

The calculation results are presented in the motion equation of the matrix. Considering certain time period $t=0,1 \cdot 10^{-5} \ldots 12 \cdot 10^{-5}$, it is possible to design graphics of reinforced concrete ring matrices motion (Figure 3 ). 

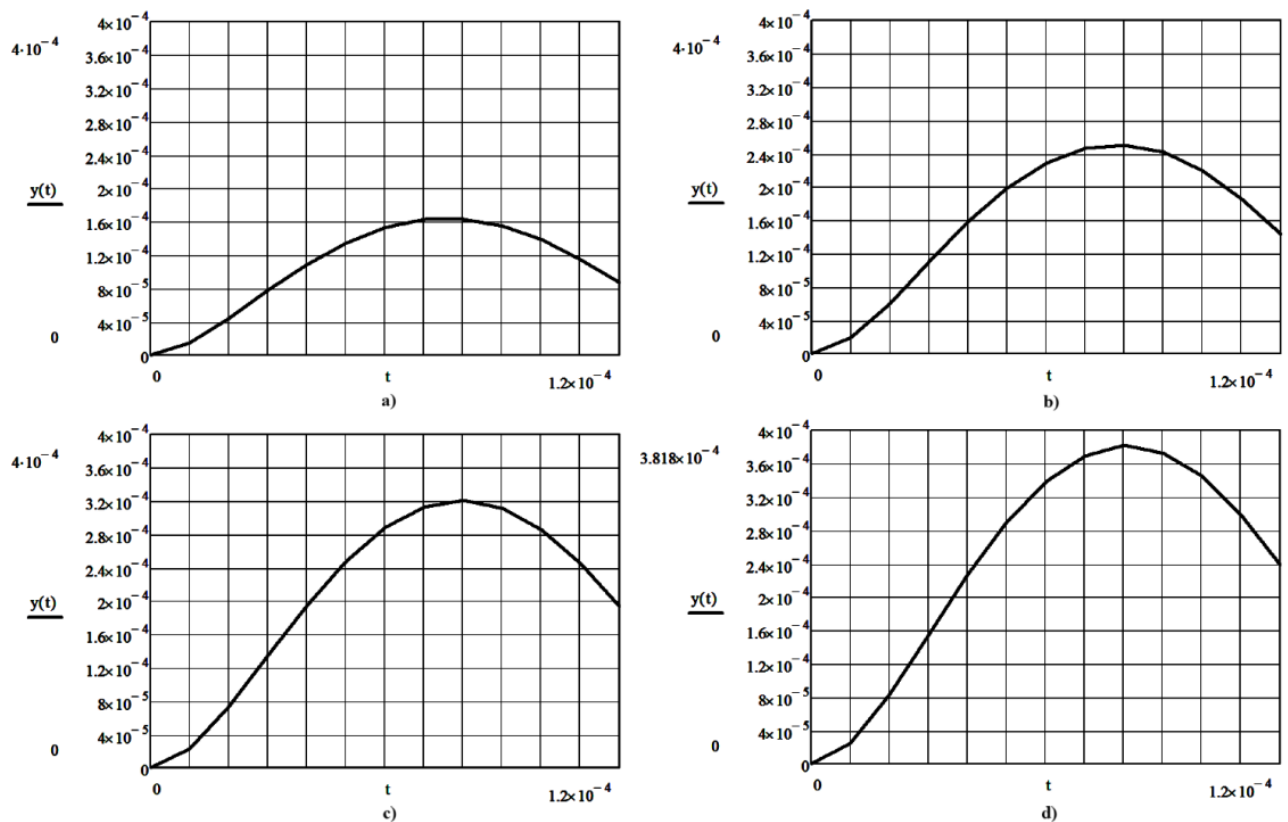

Fig. 3. Deformation graphs of reinforced concrete matrix for: a) explosive $0,01 \mathrm{~kg} / \mathrm{m} ; \mathrm{b}$ ) explosive $0,02 \mathrm{~kg} / \mathrm{m}$; c) explosive $0,03 \mathrm{~kg} / \mathrm{m}$; d) explosive $0,04 \mathrm{~kg} / \mathrm{m}$.

Having obtained the values of motion, it is possible to design graphics of relative deformation of inner and outer metal rings (Figure 4).

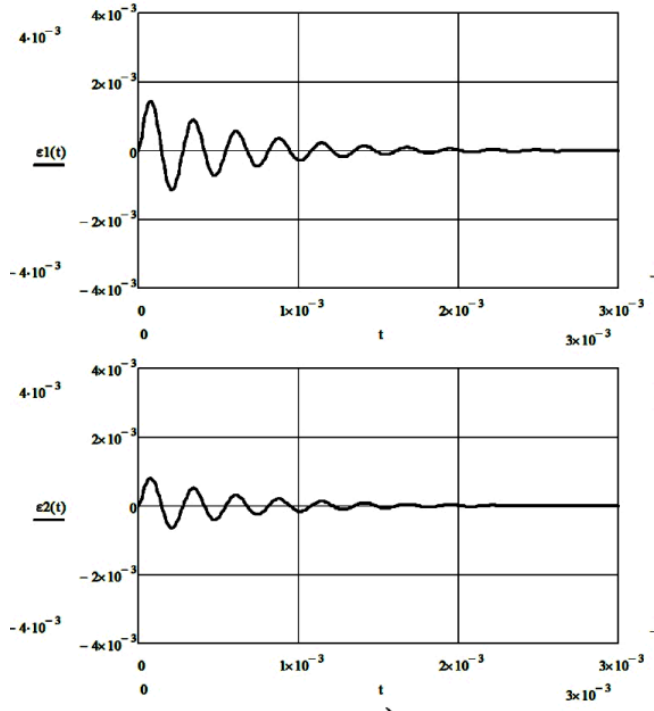

a)
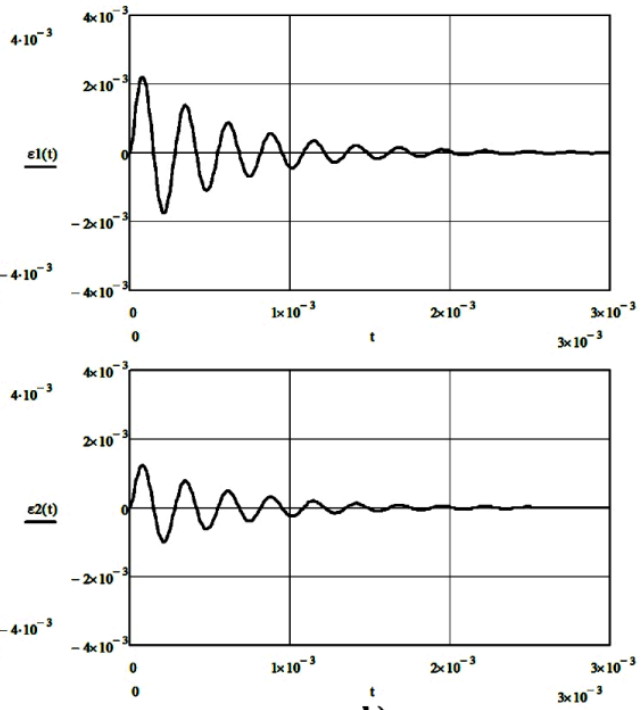

b) 


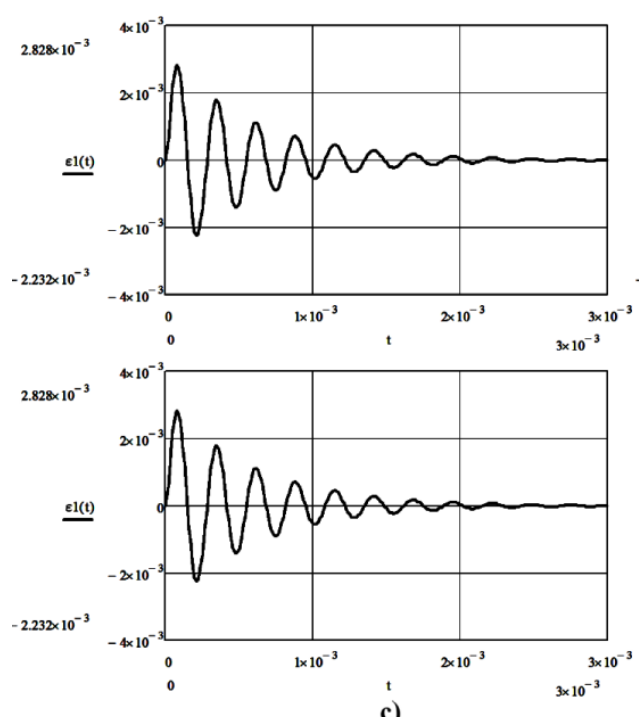

c)
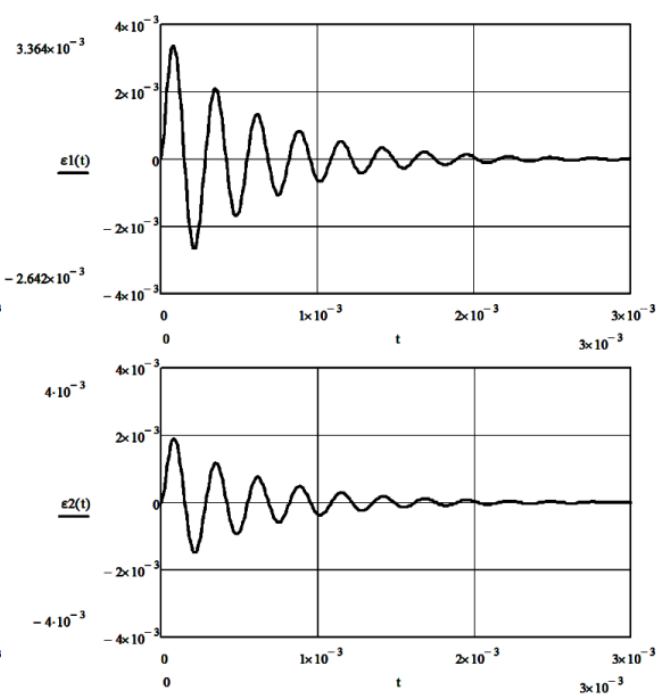

d)

Fig. 4. Relative deformation graphs of internal $\varepsilon_{1}(t)$ and external $\varepsilon_{2}(t)$ metal rings for: a) explosive $0,01 \mathrm{~kg} / \mathrm{m}$; b) explosive $0,02 \mathrm{~kg} / \mathrm{m}$; c) explosive $0,03 \mathrm{~kg} / \mathrm{m}$; d) explosive $0,04 \mathrm{~kg} / \mathrm{m}$.

The general graph of the displacement of the matrix is an approximate solution. For a more precise solution and finding the magnitudes of the movements of the rings, it is necessary to carry out the calculation, dividing the system into two components - the inner ring and the outer ring with concrete. This division is explained by the fact that at some point in time the inner ring ceases to work together and starts moving in the opposite direction. Thus, the load $P_{2}$ changes direction, i.e. sign. To find the time at which the system decays, we must substitute the value $P_{2}=0$ in equation (4).

\section{Discussion}

The developed construction gained increased density in comparison with analogue matrix construction. The compensation layer will not allow the local concrete breakage on the border of the inner metal ring and concrete sector.

The device of a hydraulic tank in the matrix construction allows rejecting expensive presses. The pressure made in a tank and transmitted on to the hardening concrete increase the concrete density. Moreover, there is a possibility to change the value of pressure in the process of construction exploitation.

The developed methodology also proves the possibility of getting higher density parameters in comparison with matrix-analogues. The obtained graphics (Figure 3,4) have high coincidence with ring matrices, calculated using the previously developed methodology. The results of comparison are described more exactly in the following paper [10].

When compiling and solving the equations of motion of the matrix (5) and its individual parts (1), (2), (3), (4), the matrix strength is calculated simultaneously, and the maximum radial deformation (displacement) is determined.

In the process of explosion stamping, matrices are required to limit the maximum displacement. Thus, when calculating the proposed method, it will be necessary to compare the obtained strain value with the maximum allowable value.

All of the above results are theoretical and need to be tested in practice. For this purpose, it is planned to produce a series of samples of ring matrices and further loading 
with explosive influences. The purpose of the tests will consist in confirming the increased strength characteristics, as well as in the considerably greater durability of the developed matrix designs.

\section{Conclusions}

In the course of the inventive activity, solutions were obtained for the reinforced concrete ring matrix for hydro explosion stamping with the addition of a compensation layer and a hydraulic tank. For this design, a calculation technique was developed that showed high convergence with earlier works of other authors. Theoretical premises for increasing strength and durability requiring confirmation by experimental studies are obtained.

\section{References}

1. S. Yilmaz, H. Ozmen, High performance concrete technology and applications (2016)

2. G. Murashkin, V. Murashkin, Vestnik of the PTO RAASN, 19, 232-237 (2016)

3. G. Murashkin, A. Snegireva, Duration of Building Materials, Products and Structures, 81-88 (2014)

4. V. Stepanov, I. Shavrov, High-energy impulse methods of metal processing (1975)

5. S. Tlustenko, V. Sytnik, Bulletin of SSAU, 36, 108-112 (2012)

6. C. Anpilov, V. Murashkin, G. Murashkin, A. Snegireva, D. Kretov, Explosive Chamber, The patent of the RF № 2016103420 (2017)

7. C. Anpilov, G. Murashkin, V. Murashkin, A. Snegireva, D. Kretov, Explosive Chamber, The patent of the RF № 2015153950 (2017)

8. A. Snegireva, Special reinforced concrete ring of matrices for gidro explosion stamping (1996)

9. G. Murashkin, D. Kretov, Materials and technologies of the XXI century, 196-201 (2016)

10. A. Snegireva, D. Kretov, Urban construction and architecture, 7, 20-24 (2017) 